\title{
EL FUTURO DE LA VIDA URBANA EN EL ESCENARIO DE LA GLOBALIZACIÓN.
}

\author{
Adolfo Benito Narváez Tijerina ${ }^{1}$. \\ Facultad de Arquitectura, Universidad Autónoma de Nuevo León
}

Remisión artículo: 30-07-2007

Remisión definitiva: 11-01-2008

Palabras Clave: Globalización, Desarrollo en las Ciudades Contemporáneas, Nuevo Urbanismo.

Resumen: La hipótesis principal de esta investigación supone que entre la crisis de los lugares, la crisis del trabajo y la crisis del Estado existen relaciones causales complejas que suponen un apoyo mutuo y que generan las condiciones para que nuestras ciudades ahora se hayan convertido en escenarios del sufrimiento y de la gran desigualdad entre las personas, lo que se refleja en estos momentos en una enorme fragmentación del espacio urbano en sus múltiples dimensiones. Se aborda el problema de la crisis del trabajo como el problema de los marginados, como la pieza de este rompecabezas en la que se hace más evidente la desigualdad.

Desde una caracterización teórica de este problema se llega a una descripción de sus efectos en el cuerpo físico de las ciudades y el territorio, estudiando la correspondencia entre el surgimiento de una sociedad radial y el de una dialéctica más acentuada del centro y la periferia de nuestra civilización. Esta revisión da pie a la elaboración de una descripción de estas periferias del sistema, que se completa finalmente con la revisión del punto de vista de un marginado. Esta revisión abre la discusión sobre la crisis de los Estados Nacionales modernos, sus efectos sobre la población y sus ciudades y el peligro real que entraña el no hacer nada frente al poder que pretende hoy instalarse como substituto del antiguo poder estatal. La parte final del capítulo es el estudio de alternativas actuales llevadas a la práctica en diversos lugares del planeta para crear otras condiciones de vida y de socialización entre las personas. Como una respuesta a la hipótesis que dio origen a este trabajo, se plantean alternativas concretas a la crisis de los lugares, a la precariedad del empleo y a la pérdida de legitimidad de los Estados Nacionales. Se hacen algunas reflexiones sobre la naturaleza del poder y las alternativas viables para establecer gobiernos más centrados en los ciudadanos. Ello da pie para plantear un futuro posible para nuestras ciudades, como una vía para crear un buen lugar para todos.

\section{Introducción}

¿Por qué se relaciona la crisis del empleo con la crisis de los lugares? Es inevitable recorrer el panorama que abren los trabajos teóricos de la década de los noventas sobre la crisis laboral (que es abundantísima) y al hacerlo se notan pautas comunes, lugares que los autores recorren una y otra vez, distopías célebres - del mundo feliz de Huxley a la ficción punk contemporánea- que visitan cada vez que tratan de sugerirnos una imagen que nos haga entender la perspectiva vital de quienes atraviesan por esta situación de desesperación y desamparo. La crisis de los lugares, como la crisis del empleo se hace una situación vital total cuando el trabajo es el centro de la biografía de la persona. ¿El trabajo, es el centro de la idea del Estado, del cuerpo de la comunidad, de la idea de familia y género?

Beck (1999) sugiere que la situación actual del empleo, hablando de cifras más bien gruesas, es prácticamente insostenible, que la manutención de los niveles actuales de desempleo en occidente es más bien un paliativo para evitar enfrentamientos que pondrían en grave riesgo a las naciones. Rifkin (1994) por su parte, sugiere que el trabajo en las fábricas en el mundo desarrollado para el 2020 , supondrá una oportunidad de empleo tan solo para el $2 \%$

${ }^{1}$ Contacto: anarvaez@far.uanl.mx 
de la masa laboral de entonces y que si los avances en el cultivo de células madre tiene el futuro que plantean los teóricos, para ese año, la agricultura para la producción de alimentos será desplazada por fábricas transformadoras de biomasa, con lo que el trabajo de 2500 millones de seres humanos podría ser solamente viable como actividad de supervivencia.

Otras cifras que hacen pensar en una reducción de la capacidad de la industria para emplear personas son las que se relacionan con el tiempo laborado. Beck (Op. Cit) señala que en el caso alemán, entre 1955 y la actualidad se ha reducido el esfuerzo individual considerablemente. Hoy se trabaja cerca del $60 \%$ de las horas laboradas en ese año a mediados del siglo XX, pero paradójicamente la productividad ha aumentado. Los alemanes han pasado de una jornada de 48 horas a una de 37.5.

Estas cifras, cuando se las enfrenta a los datos del empleo global pueden resultar inexactas. A decir de Klein (2002) la evaporación de los puestos de trabajo en occidente que los teóricos de mediados de los noventas ligaban solamente al fenómeno de la automatización de la producción, no es tal sino más bien un fenómeno de transferencia de dichos puestos de trabajo a las zonas de procesamiento de exportaciones del tercer mundo, con una transformación substancial de esos puestos fijos y plenos de derechos a otros eventuales y carentes de la menor seguridad laboral y sanitaria ${ }^{2}$.

Esta reflexión supone una serie de cosas que hay que hacer de cara al entendimiento de este fenómeno y su relación con la crisis de los lugares. Surge la necesidad de reconceptualizar la transformación de los mercados laborales frente a la globalización de la economía, que, pese a que este fenómeno como articulación multinacional de la producción tiene antecedentes importantes antes del auge neoliberal tras la época Thatcher- Reagan, ahora está más extendida, mejor construida y profundamente desregulada.

Beck sugiere que de cara a los acontecimientos de la última década es posible pensar en cuatro escenarios laborales para el futuro: el primero, supone que la integración plena en la sociedad de la información basada en la ciencia podría llevar de una sociedad fundada en el trabajo a una sostenida en el saber, como la federación de planetas en la saga televisiva Star Trek o bien a un capitalismo sin trabajo, un escenario cercano al mundo sin empleo planteado por Forrester (1997) en L' horreur économique. El segundo escenario es el de una plena globalización, que conduciría en el mejor de los casos a un milagro neoliberal: el mercado mundial, o en el peor de los casos a una competencia mundial en los mercados de trabajo bajo el esquema de una disminución de los costos de producción por la reducción de beneficios y salarios a los trabajadores.

El tercer escenario que plantea Beck es el de recurrentes crisis ecológicas, lo que supondría el reto de fortalecer las empresas sustentables y por ende el trabajo social y ecológicamente responsable, o plantearía problemas como el apartheid global, es decir la creación de zonas de desarrollo «correcto» frente a zonas a las que sea vedado el desarrollo por considerarse reservas de la biosfera, por ejemplo- y que con ello se arrastre a la miseria a las poblaciones de los países que posean estas zonas. El cuarto escenario es el de la individualización de la producción y de la sociedad, algo así como un planeta de free lancers, lo que podría conducir a un mundo de empresarios autónomos, un mundo de absoluta libertad, la individualización del trabajo y eventualmente al hundimiento de la sociedad.

Por su parte, Thomas F. Malone ${ }^{3}$ sugiere que es posible percibir dos escenarios de futuro factibles dadas las condiciones actuales de desarrollo de la ciencia y de las sociedades. En el primero de ellos, de aplicarse los principios para un desarrollo sustentable y equitativo, se conseguiría un mundo mejor educado, menos desigual que el actual y mejor articulado con la naturaleza. En este mundo, el bloque de las Américas se presentaría para el 2050 más integrado y cooperador, así, supone que las poblaciones combinadas de Estados Unidos y Canadá serían de 380 millones de personas frente a 690 millones del resto de las naciones de América; el ingreso per cápita diario de los habitantes de Estados Unidos y Canadá sería de un promedio de 185 dólares estadounidenses, frente a un ingreso per cápita del resto de los americanos de 165 dólares. El producto interno bruto combinado de Estados Unidos y Canadá sería de 23,140 trillones de dólares frente a 41,250 trillones del resto de los países americanos $^{4}$.

\footnotetext{
${ }^{2}$ Para el caso mexicano esto es terriblemente exacto: el auge manufacturero Chino de este tiempo ha destruido al menos (según las cifras oficiales) 700,000 empleos en el sector en el país en lo que va desde la incorporación del gigante asiático a la OMC hasta la actualidad.

Conferencia pronunciada en Monterrey, México en el marco de la reunión académica «El futuro de las Américas» 9 y 10 de Enero de 2004.

${ }^{4}$ Actualmente las poblaciones combinadas de Estados Unidos y Canadá suman 300 millones de personas, frente a 500 millones del resto de las naciones americanas, el ingreso per cápita en promedio de las poblaciones de Estados Unidos
} 
Pero si las condiciones de expansión del capitalismo en la actualidad prevalecieran en los próximos años, Malone avizora un escenario muy diferente para el 2050: la población de Estados Unidos y Canadá alcanzaría los 470 millones de habitantes, mientras que en el resto de los países americanos sería de 960 millones, el ingreso promedio de cada habitante de Estados Unidos y Canadá sería de 240 dólares, mientras que el de los habitantes del resto del continente sería de 45 dólares; en tanto que el producto interno bruto combinado de Estados Unidos y Canadá sería de 40,600 trillones de dólares, frente a 15,700 trillones del resto de América.

El perceptible surgimiento de un Nuevo Orden Mundial tiende a hacer prevalecer ciertas condiciones de cada uno de estos mundos que Beck y Malone imaginan al inicio del siglo XXI, marcando pautas que tienen la fuerza para reorganizar ciertos sectores de la vida de las naciones. Sin embargo, para entender desde la perspectiva de los individuos y sus comunidades las relaciones entre las crisis que estudiamos, es importante atenernos a lo particular; la especificidad de los análisis juega un papel importante en la comprensión cabal de la manera en que se liga la crisis del trabajo y la crisis de los lugares, ya que, por ejemplo, no es lo mismo tratar el problema del paro en la industria metal mecánica, que en la de los servicios o en la industria del vestido, que tienen un grado de ubicuidad muy grande frente a la menor movilidad relativa de la primera.

Las evidencias de Klein hacen suponer que la crisis laboral que hoy padece la población del planeta -por la desaparición de los puestos de trabajo o por la explotación a la que son sometidos los trabajadores del tercer mundo- tiene que ver con tres fenómenos de la administración empresarial actual: la transferencia hacia «paraísos laborales» de las actividades de la empresa más ligadas a los insumos materiales y a la ocupación de trabajadores, la supervaloración de la imagen de la empresa por sobre su producción de bienes o servicios y la manutención por parte de las empresas, como principal fuerza productiva, de una cada vez más importante masa de trabajadores sin derecho a obtener los beneficios sociales que establece el Estado.

Pese a ello, decíamos, el análisis de lo específico de cada situación vital que se abre en los diversos escenarios de la crisis laboral es importante, toda vez que cada tiempo, espacio y perspectiva establece sus propias condiciones para la situación vivida. Por lo que es posible que cada entrecruce de la crisis de los lugares con la crisis del trabajo, abra un nuevo y diferente drama vital. En una sola geografía, en una sola ciudad del tercer mundo, por ejemplo, pueden convivir la situación de los habitantes que son desplazados de su trabajo autogenerado y tradicional con carretones tirados a mula para la pepena de basura, por empresas ligadas al poder estatal, dotadas de la más moderna tecnología para esa actividad, con la situación de los desplazados de una empresa de servicios financieros que no encuentran acomodo en el curso de una crisis producto de una de las marejadas económicas de los últimos años.

La solidaridad, las redes de ayuda, el acceso a la riqueza, a la vivienda y a ciertos bienes materiales, es profundamente diferente en cada una de estas situaciones límite, lo que puede hacer igualmente diferente la relación que cada contexto plantee entre el ser y el lugar en crisis.

A contramano, es posible señalar que estas perspectivas se plantean siempre desde una situación marginal. La ciudad y sus habitantes integrados construyen frente a la persona en crisis un cerco, una barricada difícil y a veces inexpugnable. Si el Estado Nacional moderno está constituido sobre la base de la afiliación del ciudadano trabajador a la nación, la ciudad, como expresión simbólica del poder estatal, ¿está organizada espacialmente desde el trabajo?

Un buen número de teóricos del urbanismo han señalado que es posible demostrar una relación directa entre la elección del ámbito de residencia y el sitio en el que se localiza el empleo, se han desarrollado modelos matemáticos muy sofisticados que permiten observar más directamente esta relación (Narváez; 1999, 17-18) con lo que es posible afirmar que la localización de las actividades en la ciudad y la construcción de las redes de interacción entre estas tiene un alto grado de dependencia con el trabajo. Si esto es así, ¿qué pasa con los que no están integrados al medio laboral?

Las obras de la ciudad parecen excluir cada vez más a los no integrados, o así lo parece desde la perspectiva de los desempleados que deambulan por los espacios públicos que escasean en muchas ciudades industriales, y se enfrentan al furioso tránsito en las calles,

y Canadá es de 86 dólares estadounidenses, frente a 19 dólares de la población del resto de las naciones americanas. En la actualidad, el producto interno bruto combinado de Estados Unidos y Canadá es de 9,700 trillones de dólares, frente a 3,400 del resto de las naciones de América. 
incapaces de utilizar la ciudad para ninguna otra cosa que no sea ir y venir por estos canales que lo dividen todo, que sólo se pueden utilizar si tienes los recursos para moverte por ellos.

Un curioso movimiento en contra de esta clase de espacios pensados sólo para el exclusivo uso del automóvil es el que plantea el movimiento Recuperar las Calles. Se trata de iniciativas de activistas alrededor del mundo que han planteado como una forma de protesta pacífica ante la invasión del automóvil y el consumo en las áreas públicas de las ciudades, el tomar posición en calles y avenidas, organizar con un numeroso grupo de gentes un plantón, para luego hacer una fiesta, tratando de que cuando menos por unas horas (mientras son desalojados por la fuerza pública) la calle pertenezca de nuevo a los peatones. Otra curiosa iniciativa de este tipo es la que ha emprendido en San Francisco, California el grupo Critical Mass (y que luego se ha extendido a ciudades por todo Norteamérica y Europa) que consiste en hacer «coincidir» a 17,000 o 18,000 ciclistas en un punto de la ciudad para «juntos» salir de paseo. La masa de paseantes es tal, que por fuerza los automóviles quedan momentáneamente excluidos de las calles. Estos movimientos, presentes sobre todo en el primer mundo, tendrían como paralelo a los plantones y marchas de protesta de las organizaciones civiles en las ciudades del tercer mundo, evidentemente con fines políticos muy diferentes, pero igualmente efectivos para excluir de las calles al automóvil y utilizar estos espacios como algo más que canales, volviéndolos eventualmente lugares para la expresión de la libertad y la acción civil ${ }^{5}$.

Pero aún y que estos mecanismos fueran cada vez más comunes, lo que evidentemente paralizaría en muchos otros sentidos a cualquier ciudad, es notable por otros medios darnos cuenta que la producción del espacio en la ciudad está hecha a partir de intereses que poco tienen que ver con la vida cívica, la oportunidad de transitar libremente o de que cada individuo se exprese. Cada vez más los intereses de los grupos que controlan la economía planetaria se superponen a los del ciudadano común en la construcción de los espacios territoriales y urbanos. La red de carreteras construida y rehabilitada desde 1992 que dejó de tocar ciertas ciudades en México a partir de libramientos y pasos rápidos, tuvo como fin establecer las condiciones de infraestructura necesarias para el tráfico de mercancías frente al acuerdo de libre comercio de Norteamérica que se firmara en 1994. Asimismo, la eliminación de tramos de curvas en las carreteras que atravesaban las áreas montañosas del territorio, substituyéndolas por túneles, puentes o por nuevos trazados que dejaron prácticamente desconectados a pueblos y pequeñas ciudades fuera de su nuevo paso, obedeció a las exigencias de las empresas de transporte, para que las carreteras se adaptaran al estilo de manejo de sus conductores.

Un caso que hace aún más evidente esta tendencia a privilegiar los intereses de la industria y el comercio por encima de los de las sociedades civiles en la construcción de la ciudad y su infraestructura es el que alcanzó cierta notoriedad en la década de 1990 sobre la inversión pública estatal en infraestructura en Jonesboro, Arkansas con el fin de atraer a la fábrica Frito Lay. Se ha puesto de moda en la práctica del urbanismo el planear para conseguir una mayor competitividad de las ciudades, ello quiere decir, disponer el espacio urbano y su infraestructura de modo que resulte atractiva para la inversión de capital. En Ramos Arizpe, Coahuila, una comunidad del norte de México conurbada con Saltillo, la mayor obra de infraestructura urbana y de transporte no se hizo para la comunidad sino para la construcción de un parque industrial que emplea en condiciones laborales poco favorables a la población local y a cambio, las empresas multinacionales instaladas allí han disfrutado de un régimen impositivo muy favorable para ellas. Klein (2002) se refiere a este mismo hecho cuando señala el estado de las Zonas de Procesamiento de Exportaciones en el tercer mundo (lo que en México conocemos como «áreas de maquila» o «maquiladoras») frente a las ciudades y poblados que las albergan. Parece una constante el que se trate de zonas espacialmente bien planeadas y construidas (al menos en lo que atañe a las áreas exteriores de estos conjuntos de fábricas), frente a zonas de viviendas deterioradas, espontáneas y con graves problemas ambientales en las que habitan los trabajadores de esos distritos industriales.

Tal parece que las ciudades fueran construidas para albergar solamente a quienes resultan favorables para el sistema, de paso estableciendo las condiciones para que los excluidos del sistema o bien sean rechazados o de plano ni se les tome en cuenta: «Puesto que la gente es tan desesperadamente pobre... [En el tercer mundo]... no existen

\footnotetext{
${ }^{5}$ También los gobiernos y las organizaciones internacionales cierran para uso exclusivo ciertas áreas de las ciudades en las que se celebran reuniones cumbre de jefes de gobierno o de representantes de la economía de los países, causando, igual que las marchas de manifestantes o las fiestas callejeras, molestias, retrasos, inseguridad o miedo a los ciudadanos.
} 
prácticamente oportunidades para ellos en la economía formal, y resultan esencialmente irrelevantes para mucha gente en el mundo ${ }^{6}$ a lo que, en busca de la inclusión, luego los desplazados construyen sus propios mercados, establecen sus propias redes de solidaridad y se allegan propiedades y beneficios, siempre al margen. La sociedad, el gobierno, los medios, las empresas formales, etc., llaman a estos mercados y propiedades «irregulares» como señalando su imposibilidad, su ilegalidad. Luego el espacio de la ciudad se fragmenta, y de cara a esta falta de legitimidad frente a lo establecido se les excluye del desarrollo a veces en la forma de una negación de los recursos para introducir infraestructura, pavimentación, zonas públicas adecuadas, etc., o con la aportación gubernamental de recursos que apenas alcanzan para construir una pequeña parte del espacio urbano que se requiere. Esta manera de administrar los presupuestos municipales para la construcción del espacio urbano puede tener efectos perversos como el que se exacerbe la discriminación espacial en la ciudad. Los efectos de esta práctica presupuestaria son evidentes en la creación de zonas altamente diferenciadas de acuerdo con los niveles de ingreso de la población residente. Tal práctica, al igual que las que mencionábamos antes en las Zonas de Procesamiento de Exportaciones, genera guetos, islas de gran desarrollo en medio de zonas de mediano o bajo desarrollo. Los efectos sociales de tales prácticas sobre el desarrollo de las ciudades pueden ser verdaderamente adversos para la armonía de las comunidades.

Mutz (1999) opina que las condiciones de trabajo que han imperado desde los noventas han producido más inseguridad en las personas, lo que ha traído como consecuencia el que se tornen más débiles los vínculos sociales en «el seno de la familia, el círculo de amigos, la comunidad y el barrio. Nadie puede echar ya una mano al prójimo porque cada cual debe preocuparse de sí mismo y de sus más allegados» (p. 220) Esta ruptura compromete fuertemente la solidaridad social necesaria para crear y fortalecer los lazos de socialización, con lo que estructuras tan básicas como la familia empiezan a tambalearse frente a un individualismo cada día más acentuado, con lo que se han creado en el seno de las sociedades opulentas el sistema de «tutoría que acompaña, apoya y faculta a gente a la autoayuda. La gente ejerce padrinazgos para con los demás porque las redes familiares y otras redes sociales no funcionan ya» (op. Cit. p. 221)

El tránsito que se da en el tercer mundo del desempleo a la economía informal, en muchas ocasiones penoso, o se da en condiciones de carencia de los conocimientos mínimos para desempeñarse en la práctica cotidiana de algún oficio o con la urgencia de adaptar unos conocimientos y habilidades que son sobre todo aplicables al ámbito de la economía formal y del todo imprácticos para las actividades del día a día en ese otro mundo. De modo que nos enfrentamos a individuos que encuentran serias dificultades de adaptación al medio laboral, lo que deviene en muchos casos en problemas de ajuste con la sociedad a la que pertenecen.

Lo que les coloca en una situación marginal, por un lado con respecto al medio que les ha expulsado y les califica de inútiles, negligentes, flojos o de plano de que viven en una cierta ilegalidad tolerable, pero a fin de cuentas fuera de lo «aceptable», y por el otro lado con relación a los lugares, ya que el medio mismo colabora para situar a los descartados fuera de la Ciudad a través de la construcción misma de lo público, que es cada vez más solamente un espacio para el consumo y para el movimiento de los integrados. ¿Qué es vivir en esa desintegración, qué es vivir al margen?

\subsection{La vida fuera del sistema: la dialéctica del centro y la periferia.}

En la cumbre de la tierra de Johannesburgo, Sudáfrica se produjo una iniciativa interesante: elaborar una metodología que permitiera calificar el nivel de desarrollo de las regiones del planeta, de modo que pudiera elaborarse un mapa del desarrollo del mundo integrando una gran cantidad de variables (sobre infraestructura, vivienda, salud, equidad, desarrollo social, gobernabilidad, alimentación, etc.) de una manera sencilla, fácil de leer, interpretar y eventualmente, aplicar como un instrumento para la planeación del desarrollo de las regiones.

La iniciativa partía de que el análisis debería tener un nivel de resolución hasta la unidad municipal. Ello es interesante, toda vez que es relativamente fácil encuadrar a las

\footnotetext{
${ }^{6}$ Entrevista a Julie Fisher, del programa Non Profit Organization de la Universidad de Yale, citada por Rifkin (1994; 325)
} 
ciudades en esta unidad geográfica. Además pone el acento en un hecho que no deja de sorprender: que es a partir del análisis de la variación de los principales indicadores de desarrollo de las ciudades más importantes que es posible medir el desarrollo de las regiones. En otras palabras, si los países tienen en su misma geografía variaciones importantes en cuanto a su desarrollo -como el caso de México, con niveles medios a bajos de desarrollo en algunas regiones del sur y altos en el centro y norte del territorio- cabría la posibilidad de subdividirlos con fines de análisis en regiones más homogéneas y comprensibles, para así entender mejor las condiciones de un «buen desarrollo».

Por otro lado, tal instrumento facilitaría la detección de las unidades con déficit y superávit de desarrollo, aislando fácilmente las zonas más pobladas de las menos habitadas. En suma, tal iniciativa pretendía lograr tener una visión con «mayor nivel de resolución» sobre las regiones del mundo. Es interesante que la detección a este nivel geográfico de análisis se haga precisamente cuando hay una clara tendencia a la urbanización de las poblaciones del mundo. Hace suponer que es necesario dejar de contar para las mediciones de las variaciones regionales con las «unidades país» y empezar a contar más con «unidades ciudad», que, en el contexto de las prácticas empresariales y gubernamentales neoliberales, empiezan a ser las piezas de un juego de competencias por ser el destino del capital y por jugar un papel hegemónico en la toma de decisiones estratégicas de la economía-política globalizada.

El contar con esta clase de información permite tomar decisiones estratégicas en cuanto a la adopción de políticas o la elaboración de programas para favorecer el desarrollo de las regiones deprimidas. Pero también es posible utilizar estos medios para dirigir la inversión de capitales, favorecer mediante políticas o programas o tomar decisiones estratégicas en torno a las regiones en las que dado su alto desarrollo (una buena infraestructura, una población mejor educada, saludable, bien alimentada, sin problemas de gobernabilidad, etc.) el capital rendiría mejor que en las que no existieran las condiciones mínimas para que el capital se reproduzca fácilmente. Esta clase de estudios, que ponen énfasis sobre el estado de las poblaciones y su infraestructura se suman a los que hacen estudios extensos de los recursos bióticos, minerales, hidrológicos, forestales, acuícolas, etc., que son hechos con cierta regularidad por parte de empresas multinacionales o por gobiernos con el fin de detectar las áreas de recursos disponibles en el planeta. Estos estudios, sin duda pueden ayudar a discriminar con claridad las regiones más favorables para el capital y los intereses políticos de las menos favorables.

Para el caso de México fue el Instituto de Estudios sobre el Federalismo (IEF), dependiente de la Secretaría de Gobernación, el que se encargó de realizar este estudio. A su vez el IEF encargó a la Universidad Autónoma de Nuevo León (UANL) el diseño y prueba de la metodología. La UANL convocó a una serie de expertos que diseñaron un instrumento de análisis de las condiciones sociales, de salud, políticas, jurídicas, urbanas y de vivienda de las comunidades y que categorizaban el nivel de desarrollo en tres niveles, problemático (identificadas en las cartas geográficas y las de indicadores con el color rojo) con posibilidades de mejorar rápidamente (en color amarillo) y buenas (en verde) Las variables se construyeron a partir de indicadores sobre los datos tomados directamente en el campo, se elaboró una metodología y una prueba piloto en el Estado de Nuevo León.

Se hizo evidente, tras la aplicación del instrumento en el campo, algo que era del todo visible a través de la experiencia cotidiana: que el desarrollo regional, al nivel de los municipios es profundamente desigual. El Boletín de Prensa del Programa de las Naciones Unidas para el Desarrollo (PNUD) en México, presentado el 24 de junio del 2003, señala que el Estado de Nuevo León se encuentra en el segundo lugar nacional en cuanto al nivel de desarrollo humano (sólo superado por la capital del país) Evidentemente esto es cierto al nivel de las unidades estatales de la federación, pero al de los municipios la cosa cambia mucho, las divergencias entre Galeana, al sur del Estado y San Pedro (la zona más privilegiada del área metropolitana de Monterrey) son profundas, y así lo reveló el estudio de la UANL. La meta de la ONU sería construir un mapa del desarrollo de alta resolución y que revelara sus datos al nivel que es más útil: el de las ciudades, no el de las regiones o los países, dadas las condiciones del juego económico y de mercado que prevalecen en la actualidad.

Hoy este es precisamente uno de los indicadores más fáciles de utilizar por los organismos financieros mundiales o por las empresas para determinar con claridad qué es centro y qué es periferia: el de la potencialidad del lugar para la reproducción del capital. Me parece que esto es un aspecto esencial para nuestro análisis, ya que pone de manifiesto el sentido que puede adquirir la política sobre el territorio. Una comunidad es tanto más central o periférica en función de sus condiciones esenciales de desarrollo, así que es fácil decidir cuál 
región o área metropolitana es más proclive de recibir la inversión de las empresas, los organismos gubernamentales o paragubernamentales, con la consiguiente construcción de equipamiento, infraestructura, etc., y cuáles regiones no pueden ser el destino de la inversión. Esto vale tanto por el nivel de desarrollo de las poblaciones como la existencia de recursos valiosos. En ambos casos la perspectiva se basa más en la posibilidad de la explotación y menos en el fomento del desarrollo o de la conservación.

Tal noción de centralidad suele apoyarse en datos que dejan ver claramente cuáles son los aspectos que revelan el estado de desarrollo de una región. Los Sistemas de Información Geográficos han resultado una útil herramienta para revelar la distribución de las áreas proclives para la reproducción del capital sobre el territorio y los elementos que las vinculan. Un Mapa de áreas municipales en México, por ejemplo, revela con claridad que los mayores niveles de bienestar de la población se encuentran en la cercanía a los mayores centros metropolitanos del país y bordeando las principales vías de comunicación entre estas áreas y las que comunican con los Estados Unidos al oeste y al centro de su territorio. El análisis de los datos que proveen información sobre los niveles de renta nacional, los niveles de educación, de salud, de natalidad, empleo, de hacinamiento, de desarrollo urbano, etc., ayuda a revelar con toda claridad la manera en la que están organizadas las poblaciones humanas a nivel planetario.

También es posible hacer análisis multidimensionales con los datos nacionales, y así trazar mapas temáticos sobre el bienestar o el desarrollo humano, que integran diversas categorías de datos en índices únicos, como el que construyó la Organización de las Naciones Unidas como resultado de las Cumbres de la Tierra de Río y Johannesburgo para medir y localizar el grado de desarrollo multidimensional de prácticamente todas las poblaciones del planeta. La utilidad de esta información para el diseño de políticas globales de inversión y comercio es evidente.

La idea de centralidad y periferia tiene en términos más bien gruesos un significado espacial. Una serie de curiosos documentos aparecidos en diversos medios y que hacen referencia al World Atlas of the Artificial Night Sky del astrónomo italiano Pierantonio Cinzano son especialmente buenos para ilustrar esta idea. La imagen que concentra la información sobre el cielo nocturno es un mapamundi ambientado en la noche y que muestra las áreas del planeta en las que existen fuentes de emisión lumínica de cierta importancia. Estas áreas evidentemente revelan la aglomeración de asentamientos humanos que tienen un gasto de energía considerable. Hay una asociación que es muy directa entre la cantidad de energía que consume una aglomeración urbana (que se traduce en forma parcial en la iluminación pública y privada durante la noche) y el nivel de desarrollo industrial que prevalece en la zona. Así, es posible inferir basándonos tan sólo en estas imágenes y en las estadísticas sobre desarrollo, que las zonas de mayor gasto energético serán Europa Central y Occidental, el este de Estados Unidos y el área más oriental de Asia, Japón y Corea.

Los datos de gasto energético que son reportados por el Programa de las Naciones Unidas para el Medio Ambiente revelan exactamente este supuesto teórico: en la actualidad la mayor parte de la energía que se produce en el planeta es consumido por las naciones más industrializadas, mientras que las poblaciones más pobres del mundo consumen sólo una pequeña fracción de la energía del planeta. La Huella Ecológica ${ }^{7}$ que esta clase de actividades reporta en el entorno refleja sorprendentemente bien la distribución del gasto de energíaindustrialización en el planeta. La mayor huella ecológica del planeta la provocan las actividades de los habitantes de América del Norte que con una población de 299 millones de personas consumen un promedio per cápita de cerca de 12 unidades de superficie, seguidos por Europa Central y Occidental, que con 384 millones de habitantes consumen 6 unidades de superficie por persona. Europa Central y Oriental con una población de 343 millones de personas consume aproximadamente 5 unidades por habitante, Oriente Medio y Asia Central con una población de 307 millones de habitantes a su vez consume casi tres unidades de superficie por cada habitante, mientras que América Latina y el caribe, con una población de 484 millones tiene un consumo de 2.5 unidades de superficie per cápita, Asia y el Pacífico, con 3222 millones de personas consume 1.8 unidades de superficie por cada habitante (el

\footnotetext{
${ }^{7}$ En el cálculo de la Huella Ecológica interviene el consumo de materiales, alimentos y energía de la población en función de la superficie de tierra o de mar productivos necesarios para obtener estos insumos o en el caso de la energía para absorber las emisiones de anhídrido carbónico derivados de su extracción y transformación. La medición es hecha en unidades de superficie. Una unidad es el equivalente de una hectárea de productividad media mundial.
} 
promedio del consumo de los países no pertenecientes a la OCDE) y en África, cada habitante apenas consume 1.2 unidades de superficie con una población de 710 millones de habitantes. ${ }^{8}$

Los mapas de Cinzano reflejan muy bien esta realidad planetaria. La zona urbana que se extiende desde el este estadounidense hasta el centro de la gran planicie norteamericana (aproximadamente en la longitud de Chicago) es una de las aglomeraciones humanas más impresionantes, ocupando intensivamente ese territorio del planeta y de paso dejando huella del gran consumo energético de sus habitantes. Otra aglomeración importante y que tiene una extensión considerable a escala planetaria es la que se desarrolla desde el occidente europeo hacia el oriente y se desvanece en las estepas solitarias y frías del Asia Central. La zona del este asiático, la costa continental del Mar Oriental de China y del Mar Amarillo, la península de Corea y el archipiélago japonés resaltan en la oscuridad como zonas en las que la intensidad lumínica es notable, así como algunas zonas de la India. Sólo el área de Lagos en el Golfo de Guinea en el África ecuatorial, las riberas del Nilo en Egipto y la zona de Johannesburgo y Pretoria en Sudáfrica son sobresalientes en el continente africano. El resto está sumido en las sombras.

A contramano, son visibles también en estos mapas extensas zonas de oscuridad y penumbra, los territorios del Sahara lucen prácticamente vacíos, así como extensas zonas de África ecuatorial. El territorio de la selva del amazonas, que está sumergido en un mar verde de selva impenetrable, a través de los mapas se muestra inhóspito y vacío; el desierto central de Australia, la helada tundra siberiana, Groenlandia, las zonas canadienses del círculo ártico, la Antártica y los mares serían las zonas más oscuras del planeta al caer la noche. Al ver estos mapas uno fantasea con la idea de que son estos inhóspitos territorios el único vestigio intocado del planeta, se trataría de zonas fuera del control e intervención humanos. La pura imaginación de este vacío provoca vértigo y la sensación de una insondable soledad. El contacto con la no humanidad.

Estos mapas son una muy buena imagen global para entender esta idea que planteamos de las centralidades y las periferias, pues materializan muy bien los datos sobre desarrollo de los pueblos de la tierra. De las múltiples dimensiones del desarrollo, una de las que se encuentran mejor representadas en estas imágenes y en los datos sobre la Huella Ecológica de las poblaciones es la que se refiere a la renta nacional per cápita. Los países que presentan mayores ingresos por habitante del mundo (más de 40,000 dólares anuales) son dos paraísos fiscales pequeños y con muy poca población, Bermudas una isla con ingresos provenientes sobre todo de las sociedades de inversión internacionales que usan este punto muchas veces para desviar $u$ ocultar activos y transacciones monetarias y Luxemburgo, un principado europeo que es uno de los centros mundiales de clearing para las sociedades de inversión, bancos nacionales y empresas multinacionales, además de ser el origen de empresas de mala reputación como Monsanto.

Enseguida en una lista de 5 países, cuyos ingresos anuales por habitante oscilan entre los 30,000 y 39,000 dólares americanos, estas sí de las mayores economías industriales y financieras del mundo, destacan Estados Unidos y Japón. Las economías que en promedio tienen un ingreso de entre 20,000 a 29,000 dólares son las 17 que siguen, destacan en este rango Francia, Alemania y el Reino Unido.

España, Italia, Australia e Israel son cuatro de las 23 economías que tienen ingresos per cápita entre 10,000 y 19,000 dólares anuales. Siguen 83 naciones con un ingreso de 1000 a 9000 dólares por año, entre las que se encuentran países del este europeo, la Federación Rusa, las principales economías de Latinoamérica (México ocupa en esta lista de 209 países de la base de datos de la ONU el lugar 60, pero con diferencias en el ingreso con respecto a las mayores economías del orden de 7 u 8 a 1), algunos países de oriente medio y del área islámica de Asia y África, muy pocos países africanos subsaharianos y algunas islas del pacífico. Son 74 países que reportan ingresos anuales por habitante entre 90 y 900 dólares, entre los que destacan los países más poblados de la tierra: la República Popular de China y la India, prácticamente toda África, extensas zonas de Asia central y del sudeste asiático, algunos países latinoamericanos e islas del pacífico. ${ }^{9}$

Por la antípoda de este mapa de la riqueza de los países es posible trazar otro mapa de los lugares en los que el ingreso per cápita está por debajo de la línea de pobreza

\footnotetext{
${ }^{8}$ Los datos de población y Huella Ecológica corresponden al 2001.

9 Cuatro economías no reportan el dato sobre la renta nacional per cápita, por lo que no están consideradas en esta descripción: Guam, Las Islas Marinas del Norte, los Territorios Palestinos Ocupados y Las Islas Vírgenes de E.U. Cuando menos uno de estos territorios, Las Islas Vírgenes es un paraíso fiscal, por lo que en todo caso, hay que tomarse con reserva la falta de datos disponibles.
} 
generalmente aceptada (un dólar por día). Los países en los que más del $40 \%$ de su población vive por debajo de la línea de pobreza ${ }^{10}$ serían países centroamericanos, Perú, la mayoría de los países africanos y la India; los países en los que del $25 \%$ al $40 \%$ de la población se encuentra en esta situación serían de Latinoamérica Brasil, Ecuador y Panamá; de África, Mauritania, Nigeria, Etiopía, Guinea y Botswana, de Asia la República Popular de China, Taiwán y Filipinas.

Los países en los que su población en extrema pobreza representa del $16 \%$ al $24 \%$ del total de sus habitantes serían de Latinoamérica, Costa Rica y la República Dominicana; de África, Costa de Marfil, Tanzania y Sudáfrica. De Europa solamente Rumania. Los países en donde la población en extrema pobreza representa de un $6 \%$ a un $15 \%$ serían de América Latina, México, Venezuela, Colombia, Bolivia y Chile; las zonas Saharianas musulmanas y algunos países del medio oriente y del Asia central, algunos los países de Europa del Este y algunos países del sudeste Asiático. Los países en los que menos del $5 \%$ de la población se encuentra en estas condiciones serían La federación Rusa, algunos los países de Europa del Este y del Asia Central. Europa Occidental, Norteamérica (exceptuando a México), Japón, Corea del Sur, Australia y Nueva Zelanda según los datos de la ONU no tienen población en extrema pobreza.

Una jerarquía sobre la base de la población pobre en el mundo revela que las personas que viven con menos de un dólar al día son en Asia Meridional el $43 \%$ de la población, en el África al sur del Sahara el $39 \%$ de la población, en Asia Oriental y el Pacífico el $26 \%$, en América Latina y el Caribe el $24 \%$, en el Oriente Medio y el Norte de África el $4 \%$ de la gente y en Europa y Asia Central el $3 \%$ de la población.

¿Estas geografías que tienen que ver con los ingresos, o la falta de estos, son buenos indicadores de la centralidad y la externalidad en el sistema mundial? Para tener una idea de la utilidad de estos datos habríamos que ver cómo se comportan otros indicadores frente a estos. Veamos: La población mundial observa desde hace tiempo una clara tendencia a la urbanización, no sólo por el crecimiento de la población en las ciudades, sino por la migración desde los medios rurales. Es un hecho que se observa claramente en las estadísticas y en los censos nacionales el de la desaparición gradual de lo rural.

Según datos de la división de población de la ONU, las más altas tasas de crecimiento de la población urbana no se encuentran en las naciones industrializadas, sino en las naciones en vías de desarrollo. Entre 1980 y el año 2000 los países de menores ingresos saltaron de una población urbana global de 381 millones de personas a 772.5 millones; en los países de ingresos medio- bajos la población urbana pasó de aproximadamente 515.6 millones de habitantes a 987.4 millones; en los países de ingresos medio- altos se presentó un incremento similar en esos 20 años, pasando de una población urbana de 240 millones a una de 388.6. En los países más ricos, la población urbana creció menos en términos relativos, ya que se movió de 605.2 millones de personas a 741.9 millones, lo que implicó un incremento de tan sólo una sexta parte en el mismo período, frente a casi la duplicación de la población urbana en el contexto de los países más pobres del planeta.

Se ha hecho evidente que las más altas tasas nacionales de urbanización se encuentran en los países más pobres. Tres países africanos se encuentran a la cabeza en este sentido, Liberia, con una tasa de incremento de su población urbana de $6.82 \%$ anual, Burundi con $6.38 \%$ y Sierra Leona con $6.32 \%$. A pesar de que Liberia tiene una renta nacional per cápita de 169 dólares anuales, situándose en el lugar 197 del rango de niveles de ingreso de 209 países, Burundi tiene una renta nacional promedio de 110 dólares al año por habitante, situándose en el lugar 201 de este rango y Sierra Leona tiene 164 dólares anuales de ingreso promedio por habitante, situándose en el lugar 199 del rango. Y por otro lado, las tasas menores de urbanización las tienen los países del extinto bloque socialista y del mundo desarrollado.

En el 2001 el $26 \%$ de la población urbana mundial era el de los habitantes de los países con productos internos altos, el $13 \%$ de los países con productos internos medio altos, el $34 \%$ correspondía a los países de productos nacionales medios bajos y el $27 \%$ a los países con menores niveles de renta nacional. Lo cual explica algunas cosas, pues es claro que existe una relación muy importante entre la renta nacional y el tiempo de consolidación de las poblaciones urbanas en las ciudades. Los países con más altos porcentajes de su población habitando en ciudades son normalmente los más desarrollados. La jerarquía de países en cuanto a su nivel de urbanización es encabezada por los que están también a la cabeza en los

${ }^{10}$ Los datos se refieren a información estadística entre 1981 y 1995. 
niveles de renta nacional por habitante, los países más ricos tienen niveles de urbanización de $78 \%$ y con tendencias a incrementarse aún más con los años, mientras que los países con menores ingresos tienen niveles de urbanización de la población de $31 \%$. Los países de rentas nacionales medio altas, entre los que es posible contar a las economías más desarrolladas de América Latina tienen niveles de urbanización en la actualidad cercanos a los de los países industrializados, pero con menores niveles de acceso a servicios de sanidad, por ejemplo. Mientras que en países del primer mundo el acceso a servicios de agua potable y alcantarillado de las poblaciones urbanas es del $100 \%$, en estos otros países en desarrollo a los que aludíamos antes, sería del orden del $87 \%$.

Los países más industrializados no sólo son los más urbanizados, también son los menos eficientes hablando energéticamente y los que más contaminantes vierten al medio por su gran consumo energético: mientras que 856 millones de personas de los países desarrollados (habitantes de ciudades o no) consumen el $58 \%$ de los recursos energéticos del planeta (con la consiguiente carga para el ambiente) 3914 millones de personas consumen el $38 \%$ y 979 millones de habitantes del mundo (los que perciben los menores ingresos y que viven en el tercer mundo) apenas y consumen apenas el $4 \%$ de la energía del planeta. Los países ricos también son los que tienen más habitaciones en las viviendas y en donde éstas son más grandes, en Canadá hay dos habitaciones por residente en promedio, mientras que en la India dos habitaciones tienen que ser compartidas por cinco personas en promedio.

En los países más urbanizados y desarrollados también existen más expectativas de vida: mientras que en Japón las mujeres viven hasta los 85 años en promedio, en Zambia viven sólo hasta los 33 años en promedio ${ }^{11}$; existen más expectativas de educación formal: mientras que en Noruega se espera que cualquier niño permanezca en promedio 16 años de su vida en la escuela, en Venezuela la población estará 10.5 años, y en Mali estará un promedio de 2.1 años. Los países ricos tienen menor mortalidad infantil, pero más desempleo abierto que los países en desarrollo ${ }^{12}$.

Estos hechos pueden ayudarnos a dibujar mejor el paisaje que nos permita entender el sentido global de la desigualdad que se plantea entre el centro y la periferia, entre los integrados y los desplazados. Es evidente que existen regiones que se encuentran en el centro del planeta y que en muchos casos han segregado en largos procesos históricos a grandes regiones del mundo hacia una periferia que primero ha padecido la explotación de sus poblaciones y sus recursos, que se ha hecho dependiente para su propio desarrollo de la prosperidad de estas regiones centrales, para que luego estas poblaciones explotadas y dependientes poco a poco sean desplazadas a sitios en los que ya no existan en el sistema. Situándose en un limbo del desarrollo, que Forrester (1997) ha llamado el lugar de los invisibles.

Estas regiones, si acaso, existen para los centros del sistema como fuentes de recursos, pues los de sus territorios están agotándose o están francamente extintos. Para que nos demos una idea de lo que me refiero, basta comparar dos regiones del mismo vecindario en la geografía planetaria, situadas en los extremos del desarrollo en la actualidad y ligadas por largos y penosos procesos de colonización y explotación: Europa Occidental y África Occidental. El patrimonio nacional en ambos territorios tiene una composición muy diferente. Mientras que en Europa Occidental está compuesto en su mayor parte por recursos humanos, representando el $75 \%$ de éste, mayor en términos absolutos por unos 120 millones de personas y en términos relativos por una diferencia de tiempo promedio de acceso a la educación formal de al menos 10 años (es decir que la población europea estudiará en la escuela un promedio de 10 años más que la africana) en menor medida el patrimonio estará integrado por el capital físico (ciudades, fábricas, infraestructura) con un tiempo de consolidación en muchos aspectos distante del de los recursos de capital físico de África

\footnotetext{
${ }^{11}$ Para Francis Fukuyama (2003) la transición demográfica que experimenta el mundo hará que en el futuro se escinda aún más que hoy la brecha entre el norte y el sur, ya que hacia el 2050 prevé un mundo desarrollado con promedios de edad entre los 54 y los 58 años, frente a unos promedios del tercer mundo del orden de alrededor de 20 años, lo que afectará, según el politólogo estadounidense, la capacidad de respuesta bélica de occidente frente al mundo periférico, más masculino y competitivo, frente a un centro más femenino, de edad avanzada y conformista. Un dato interesante sobre esta transición es el de que se prevé que para el 2050 , en el mundo desarrollado sólo el $5 \%$ de la población contará con parientes en líneas colaterales, lo que supone líneas sucesorias ténues y débiles, frente a la abundancia de la parentela en los países periféricos, que se prevé, permanezca por más años.

${ }^{12}$ Las tasas de desempleo abierto son mayores hoy en día en las zonas devastadas por la violencia étnica y en el ex bloque socialista, en la mayor parte de los casos, que en el occidente desarrollado. A partir de 1998 América Latina ha sufrido un incremento en el desempleo, así que el panorama de mediados de la década de los noventas tiende a cambiar; lo que permanece como una sombra perversa es la clase de empleo, de paga y de acceso a la seguridad social que ofrece para sus ciudadanos el primer mundo contra la que viven los habitantes de los países en desarrollo.
} 
Occidental unos dos mil años, y además está integrado por un patrimonio natural que para Europa del oeste representa tan sólo el $2 \%$ del total de la riqueza nacional.

El panorama africano es muy diferente: en cuanto a sus recursos humanos estos representan un $60 \%$ del patrimonio nacional, sus activos de capital físico representan el $19 \%$ de la riqueza y sus recursos naturales representan el $21 \%$ del patrimonio de estos pueblos. Este último aspecto del patrimonio es en la actualidad una de las piezas clave de la riqueza de estos países, ya que no sólo existe en extensión (que es considerablemente grande, si no que se lo pregunten a Shell Oil en sus campos de explotación y contaminación en Nigeria), sino en diversidad. Ahora que las industrias de lo vivo han cobrado una inusitada importancia económica, estos lugares parecen ser los yacimientos más grandes de riqueza que posee la humanidad (Hertz, 2002).

No obstante esta riqueza, esta tierra aún sigue existiendo como un yacimiento nada más para los países y las empresas del occidente industrializado y rico. Mientras que la tierra urbanizada y estéril de las ciudades occidentales se vende como oro, la tierra rica de los pueblos de la periferia se vende a centavos la hectárea. Tal parece que esta disparidad esté más relacionada con una riqueza simbólica que con una riqueza real. Klein (2002) ha señalado cómo la naturaleza actual del capital descansa más que sobre los activos físicos o sobre la producción real, en la imagen. La riqueza de las naciones parece estar más relacionada con el dinero que con las gentes, sus construcciones, su trabajo y su producción. Y este parece ser el meollo de la cuestión, el dinero, que es en realidad un activo simbólico, empieza a representarse cada vez más a sí mismo y no a los bienes o a los servicios que intercambia. El dinero se reproduce, y en esa reproducción simbólica va siendo cada vez más distante del mundo, se va virtualizando, justamente en el sentido que Avery (2001) le da al término, como la construcción de otra realidad alterna que actúa en potencia sobre ésta. Y en este camino se va despojando de todo lo que tenga que ver con un soporte físico concreto, el dinero, en muchos casos existe únicamente como un conjunto de datos asentados en medios ópticos o magnéticos, pero tiene la capacidad de reproducirse aún al margen de los bienes reales a los que hace tiempo daba valor.

Esta capacidad de crecer del dinero es mayor en los centros del sistema que en las periferias. La riqueza de las naciones y de las empresas más poderosas del planeta, a los ojos de la gente, es lo que les da mayor importancia, lo que en muchos sentidos les hace parecer enormes e inalcanzables. La posesión o la carencia de este valor de valores que es el dinero, tal y como lo entendemos hoy, profundamente desconectado de lo material, autónomo en los medios pero determinante de las relaciones entre las naciones y los pueblos, establece la noción de centro y la sensación de encontrarse en la periferia.

Es evidente además que el medio de reproducción ideal del dinero es el mundo urbanizado de hoy. Las inversiones en activos reales, como las relacionadas con actividades extractivas, agropecuarias, manufactureras, etc., han sido en la actualidad superadas por la inversión en activos simbólicos, alcanzando magnitudes de 10 a 1 . El medio más favorable para el intercambio de tales activos parece ser la ciudad. La revolución en las comunicaciones y en la informática, huelga decirlo, ha jugado un papel fundamental, tanto en la desaparición de los soportes materiales de la riqueza, como en su impresionante velocidad y magnitud de reproducción.

Los mapas de Cinzano revelan mejor que muchos otros medios estas centralidades de la riqueza, ya que, como lo mencionábamos antes, los sitios más urbanizados del planeta y en donde las ciudades están más consolidadas y mejor construidas, son en donde se reproduce mejor el capital. Hay que decir que además de una mayor urbanización del territorio y una mejor construcción de sus ciudades, las centralidades del sistema poseen unas redes de intercambio mejor estructuradas. Es innegable que la imagen del este estadounidense que presenta la porción americana del mapa de Cinzano revela mejor que otras imágenes la existencia de una megápolis a nivel planetario que aglomera cuando menos a 220 millones de personas, actualmente concebida como un conjunto de áreas urbanas, pero con una coherencia tal, de tal manera interconectadas y con dependencias mutuas tan fuertes, que revelan una naturaleza sistémica que hace pensar en una sola área urbanizada.

El mundo occidental ha establecido tal vez desde la industrialización, las condiciones para su desarrollo, incluso definiéndose y de paso definiendo para los demás pueblos de la tierra los valores de éste. La aceptación de tales valores nos ha llevado a pensar que es a través de la fórmula occidental del progreso que nuestras naciones alcanzarán el bienestar (un bienestar evidentemente concebido fuera de nuestro propio mundo), por lo que en muchos casos los proyectos de desarrollo imitan a los proyectos de los centros del sistema. ¿Es esto 
justo para nuestras naciones? Los valores del desarrollo, sobre los que se asienta el modo de vida del occidente industrializado, son un acuerdo, descansan en ideas, mitos e imágenes del progreso. Pueden ser concebidos desde una cierta perspectiva como algo tan irreal como el acuerdo sobre el que descansa el valor del dinero, que le otorga «materialidad» a esos valores.

Pero en medio de ese acuerdo, y a pesar de él, muchos pueblos sufren, no están en el acuerdo, eso es todo, o si no, de qué manera nos podemos explicar que el trabajo de una persona, el mismo trabajo que se ejerce en el día a día en la misma empresa multinacional sea tazado en el tercer mundo a veces hasta a un décimo del valor que se paga por él en el primer mundo, y esto sin que el valor de los bienes que se producen o se venden cambie en absoluto en el primer mundo y en la periferia de éste. El acuerdo sobre el desarrollo y sus valores de intercambio es más benéfico para el centro que para la periferia, y esto afecta las posibilidades de desarrollo de los pueblos de una manera dramática, ya que establecidas las condiciones para una valoración desigual del trabajo, de los bienes, los servicios, los recursos, etc., siempre habrá mayor ventaja, mayor ganancia para los que residen en el centro y detentan el poder. Lo de los de afuera, lo de los otros, siempre es de segunda, pero pasando la frontera de ese centro protegido y excluyente vale como el oro. Es como si los excluidos vivieran siempre en un mundo que no alcanza a ser como ese paraíso perfecto al que van siempre nuestros sueños y nuestros afanes, como si este fuera un mundo defectuoso, de segunda mano.

El desarrollo de la centralidad, la idea misma de progreso, poco a poco parece alinearse con la geografía del dinero, y como un efecto que revela la naturaleza y valores del sistema, aparta cada vez más en cuanto a la posesión de la riqueza a las centralidades de las periferias. Pero si el dinero es sólo un acuerdo, el depósito de unas ideas en un soporte simbólico compartido, pero del todo irreal, ¿no será posible la cura de esa desigualdad a través de la desaparición de ese valor?

Un razonamiento así es fácil, pero ¿quién se atreve hoy a dudar de la realidad del valor del dinero, si cuando no lo tenemos no podemos comer, movernos, educarnos, pagar la renta, tomar agua, comunicarnos, informarnos, tener luz por las noches, divertirnos? ¿Será posible un mundo sin dinero? ¿Qué clase de acuerdo necesitamos para pulverizar las centralidades y distribuir el bienestar de una forma más justa?

Vale decir que la centralidad también se asienta en la fuerza, no sólo en el dinero. La violencia y la muerte fueron las armas del imperio para sojuzgar a los que había que saquear y explotar y ahora han resurgido a escala planetaria de una forma atroz y atemorizante, ¿quién olvida al pueblo afgano hundido en el horror de unos ataques devastadores que se hicieron en nombre de una libertad y una justicia que no los alcanza y que ocultaba una cara maligna e interesada en hacer andar una industria de guerra que por inoperante empezaba a quedar obsoleta? Es un hecho que las mayores industrias bélicas son las del occidente industrializado (Estados Unidos en el primer lugar e Inglaterra en el segundo) Por lo que la violencia, sea esta real o simbólica, juega también un papel decisivo en la definición del centro contra la periferia.

Estas imágenes nos pueden llevar a unas conclusiones sobre la geografía del desarrollo que son importantes para este análisis: la definición espacial de las centralidades está ligada fuertemente a la de las áreas urbanizadas; que estas interactúan de tal manera en el occidente desarrollado que es inútil considerarlas como entidades dependientes de la realidad socioeconómica, política y demográfica de los países. Cada área urbanizada actuaría hoy como una pieza de un sistema mayor y multinacional en competencia hegemónica con otros sistemas.

Ello pone de relieve que para el análisis de las centralidades es necesario desagregar estas piezas de las cuentas nacionales y empezarlas a considerar como entidades al margen de las naciones, vale empezar a considerar la necesidad de descubrir los límites e interconexiones de estas extensas áreas urbanizadas, que muy bien pueden estar descansando en los territorios y sus medios de comunicación o en redes de tránsito de valores de naturaleza no espacial. Tal vez esta es la manera en la que está estructurada hoy la geografía de la riqueza. 


\section{Bibliografía.}

Arocena, José Identidades y tecnologías: la lógica del actor y la racionalidad instrumental. Memorias del coloquio Identidad, desarrollo y viabilidad de las ciudades patrimoniales. México: Université Laval- Universidad de Guanajuato, 2003.

Augé, Marc. Ficciones de fin de siglo. Barcelona: Gedisa, 2001.

Avery, Christopher. Business and Human Rights in a Time of Changes. Londres: Amnesty Intl British Section, 2001.

Barber, Benjamín R. Un lugar para todos. Cómo fortalecer la democracia y la sociedad civil. Barcelona: Paidós, 2000.

Bauman, Zygmunt. La globalización consecuencias humanas. Brasil: Fondo de Cultura Económica, 1999.

Bauman, Zygmunt. Trabajo, consumismo y nuevos pobres. Gedisa: Barcelona, 2003.

Beck, Ulrich, et alt. Un nuevo mundo feliz. Barcelona: Paidós, 1999.

Bentley, lan, et alt. Entornos vitales. Barcelona: Gustavo Gili, 1999.

Boltvinik, J. y Hernández, E. Pobreza y distribución del ingreso en México. México: Siglo XXI, 1999.

Bourdieu, Pierre (dir.). La miseria del Mundo. México: Fondo de Cultura Económica, 1999.

Cole, Richard, Rodríguez, Alejandro, Kincaid, John. Opinión pública sobre el federalismo en México. En Narváez, Adolfo. Aedificare 2004. Monterrey: Universidad Autónoma de Nuevo León, 2004.

Cross, Gary.Time and Money: The Making of Consumer Culture. Nueva York: Routledge, 1993.

De Soto, Hernando. El misterio del capital. México: Diana, 2000.

Forrester, Viviane. El horror Económico. Buenos Aires: Fondo de Cultura Económica, 1997.

Frade, Laura. Financiamiento para el desarrollo, la esquizofrenia global institucionalizada. Monterrey: Revista CATHEDRA de la UANL, año 1 num 1, 2001.

Fuentes, Carlos. Nuevo Tiempo Mexicano. México: Aguilar: 1994.

Fukuyama, Francis. El fin del hombre. Consecuencias de la revolución biotecnológica. Barcelona: Ediciones B, 2003.

González Arellano S. \& Villeneuve P. Desigualdad social en el espacio urbano en México. CIUDADES. Puebla: Red Nacional de Investigación Urbana, 2002. Vol 53, pp 51-58.

González Casanova, Pablo; Aguilar Camín, Héctor (coords). México ante la crisis. México: Siglo XXI, 1987.

Hertz, Noreena. El poder en la sombra. La globalización y la muerte de la democracia. Barcelona: Planeta, 2002.

Horowitz, Irving. Los anarquistas, 1. La teoría. Madrid: Alianza Editorial, 1982. 
Huntington, Samuel. The clash of civilizations and the remaking of world order. Nueva York: Simon \& Shuster Trade Paperbacks, 1997.

INEGI. Estadísticas históricas de México (volúmenes 1 y 2). Aguascalientes: INEGI, 1994.

INEGI. XI censo general de población y vivienda resultados definitivos. Aguascalientes: INEGI, 1997.

Kaplan, Marcos. Sociedad, política y planificación en América Latina. México: Universidad Nacional Autónoma de México, 1980.

Klein, Naomi. No logo. Barcelona: Paidós, 2002.

Martín Juez, Fernando. Contribuciones para una antropología del diseño. Barcelona: Gedisa, 2002.

Meda, Dominique. El trabajo. Un valor en peligro de extinción. Gedisa: Barcelona, 1998.

Mutz, Gerd. El fin de la cultura de la caravana. En: BECK, 1999.

Narváez T. Adolfo Benito. La ciudad, la arquitectura y la gente: diseño participativo y didáctica medioambiental 2. Monterrey: UANL, 1999.

Narváez T. Adolfo Benito. Arquitectura y desarrollo sustentable. Mendoza, Argentina: Idearium, 2000.

Narváez T. Adolfo Benito, editor. La casa de América. Cuba- México: UANL-UC, 2001.

Narváez T. Adolfo Benito, editor. Hábitat y vivienda en América. Cuba- México: UANL-UC, 2002.

Narváez T. Adolfo Benito. Teoría de la Arquitectura. Aproximación a una antropología de la arquitectura y la ciudad. México: Trillas, 2004.

Narváez T. Adolfo Benito. Ciudades Difíciles. El futuro de la vida urbana frente a la globalización. México: Plaza y Valdés, 2006.

Ortega Ridaura, María Isabel. Política Fiscal e Industria en Monterrey 1940- 1960. Monterrey: UANL, 2000.

Parker, Mike, SLAUGHTER, Jane. Choosing Sides: Unions and the team Concept, Detroit: Labor Notes, 1988.

Pirie, Madsen. Reasons for privatisation. En Phillip Morgan (ed.) Privatization and the welfare State. Londres: Dartmouth Pub, 1995.

Riddell, Peter. The Thatcher era and its legacy. Londres: Blackwell Publishers, 1992.

Riechman, J. Fernández, F. Redes que dan libertad. Barcelona: Paidos, 1995.

Rifkin, Jeremy. El fin del trabajo. Nuevas tecnologías contra puestos de trabajo: el nacimiento de una nueva era. Prólogo de: Heilbroner, Robert. México: Paidós, 1994. 